\title{
Processos de reintegração de posse das escolas ocupadas pelos estudantes no Paraná: a ideologia burguesa do aparelho judiciário e policial
}

\author{
Patrícia Correia de Paula Marcoccia ${ }^{1}$ \\ https://orcid.org/0000-0001-5407-7685
}

\author{
Rodrigo Diego de Souza ${ }^{3}$ \\ https://orcid.org/0000-0002-4157-6116
}

\author{
Maria de Fátima Rodrigues Pereira ${ }^{2}$ \\ https://orcid.org/0000-0002-8511-2313 \\ ${ }^{1}$ Universidade Estadual de Ponta Grossa, Departamento de Pedagogia, Programa de Pós-Graduação em Educação, Ponta Grossa, PR, \\ Brasil \\ ${ }^{2}$ Universidade Tuiuti do Paraná, Departamento de Pedagogia, Programa de Pós-Graduação em Educação, Curitiba, PR, Brasil \\ ${ }^{3}$ Universidade Federal de Santa Catarina, Departamento de Metodologia de Ensino, Programa de Pós-Graduação em Educação Científica \\ e Tecnológica, Florianópolis, SC, Brasil
}

\begin{abstract}
Processos de reintegração de posse das escolas ocupadas pelos estudantes no Paraná: a ideologia burguesa do aparelho judiciário e policial
\end{abstract}

Resumo: O objetivo deste artigo é interpelar e problematizar as razões avocadas para a reintegração das escolas estaduais do Paraná pelos aparelhos jurídico e policial, levando em conta seu caráter ideológico. Os processos foram analisados à luz da teoria social marxista e do método da economia política. Os procedimentos utilizados neste estudo são a pesquisa bibliográfica e a pesquisa documental, decorrente das ações de mandados de reintegração de posse por parte do Estado do Paraná. O estudo possibilitou apontar que as ações de reintegração de posse das escolas ocupadas no Paraná, firmadas por meio dos especialistas do Estado burguês, apresentavam uma inversão do real quando utilizavam o mesmo argumento dos estudantes secundaristas para solicitar a reintegração de posse forçada sob a justificativa do cumprimento do direito à educação, ou seja, converteram as manifestações dos estudantes e a luta pelo direito à educação em (des)obediência e assunto de força policial.

Palavras-chave: Processos de reintegração de posse. Ocupação das escolas. Estudantes. Ideologia burguesa. Aparelho judiciário e policial.

Processes of removing students that occupied schools in Paraná: The bourgeois ideology of the judiciary and police

Abstract: This article questions and discusses the reasons the judiciary and the police offered in the court's decision that instructed the removal of students from occupied schools in the Brazilian state of Paraná, considering the decision's ideological nature. The processes were analyzed in the light of Marxist social theory and the approach of the political economy. The study used bibliographic research and documentary research procedures, resulting from the court's decision for the removal of the students in favor of a request of the state's government. The study pointed out that the acts of removing the students from the occupied schools in Paraná, guided by the decisions of specialists representing the bourgeois state, presented an inversion of the real situation. The courts' decision used, to remove the students by force, the same arguments the high school students used to occupy the building: the right to education. That is, the judiciary and police apparatus transformed the students' demonstrations and the struggle for the right to education into (dis)obedience and a matter of police force. Keywords: Processes of removal. Occupation of schools. Students. Bourgeois ideology. Judiciary and police apparatus.

Recebido em 01.10.2018. Aprovado em 20.11.2018. Revisado em 29.04.2019.

(C) O(s) Autor(es). 2019 Acesso Aberto Esta obra está licenciada sob os termos da Licença Creative Commons Atribuição-NãoComercial 4.0 Internacional (https://creativecommons.org/licenses/by-nc/4.0/deed.pt_BR), que permite copiar, distribuir e reproduzir em qualquer meio, bem como adaptar, transformar e criar a partir deste material, desde que para fins não comerciais e que você forneça o devido crédito aos autores e a fonte, insira um link para a Licença Creative Commons e indique se mudanças foram feitas. 


\section{Introdução}

Este texto apresenta e analisa os processos de reintegração de posse das escolas estaduais do Paraná ocupadas pelos estudantes secundaristas em 2016, à luz da teoria social marxista e do método da economia política. O pressuposto que daí decorre e nos orienta é que "não é a consciência dos homens que determina o seu ser, mas, ao contrário, é o seu ser social que determina sua consciência”. (MARX, 2008, p. 47). Ou seja, é a própria prática social, as relações que os homens travam entre si ao produzirem a vida que determinam suas ideias, suas concepções.

Nesse sentido, assenta-se que as relações políticas, jurídicas, as formas de Estado, não podem ser captadas "[...] nem a partir de si mesmas, nem a partir do assim chamado desenvolvimento geral do espírito humano, mas, [...] elas se enraízam nas relações materiais de vida, [...] [e] a anatomia da sociedade burguesa deve ser procurada na Economia Política”. (MARX, 2008, p. 47).

Essa abordagem possibilita interpelar e problematizar as razões avocadas para a reintegração das escolas, pelos aparelhos jurídico e policial, levando em conta seu caráter ideológico.

Efetivamente, trata-se de considerar que as ideias dominantes se tornam dominantes porque mantêm relação com as relações materiais dominantes. Por sua vez, a classe burguesa não expõe como uma determinada relação social se torna dominante no seio da prática social, pelo contrário, oculta os conflitos entre as classes e converte as lutas sociais em obediência e assunto de força policial.

O procedimento utilizado neste estudo é a pesquisa bibliográfica com base em pesquisas anteriores, documentos impressos e pesquisa documental decorrente das ações de mandados de reintegração de posse por parte do Estado do Paraná, boletins de ocorrência e a Ata de Assembleia do Conselho Escolar de uma escola ocupada.

Este texto está estruturado da seguinte forma: primeiramente, apresenta dados sobre a situação das escolas ocupadas no Estado do Paraná; e, em seguida, interpela e problematiza as razões avocadas para a reintegração das escolas, pelos aparelhos jurídico e policial, levando em conta seu caráter ideológico.

\section{A ocupação das escolas estaduais no Estado do Paraná e o caráter ideológico ${ }^{1}$ nos processos de reintegração de posse}

Em 2016, estudantes secundaristas ocuparam suas escolas em protesto e resistência às políticas do Governo Temer, nomeadamente contra a Reforma do Ensino Médio, inicialmente pela Medida Provisória (MP) 746/2016 (BRASIL, [2017b]), posteriormente a Lei no 13.415, de 16 de fevereiro de 2017 (BRASIL, [2017a]), ao reformular o art. 36 da Lei no 9.394, de 20 de dezembro de 1996 (BRASIL, [2019]), o qual incidiu no denominado Novo Ensino Médio e a Proposta de Emenda à Constituição (PEC) 55.

De modo geral, essa reforma retira as disciplinas de Língua Espanhola; condensa as disciplinas de História, Geografia, Artes, Filosofia e Sociologia em Ciências Humanas, condensa as disciplinas de Química, Física e Biologia em Ciências da Natureza; e mantém como obrigatórias apenas as disciplinas de Língua Portuguesa, Matemática e Inglês. Nesse sentido, o novo Ensino Médio passa a oferecer no primeiro ano a formação básica, a qual até então é oferecida nos três anos do Ensino Médio, e após este um ano a formação dos estudantes passa para um dos itinerários formativos, sendo: I - linguagens e suas tecnologias; II - matemática e suas tecnologias; III - ciências da natureza e suas tecnologias; IV - ciências humanas e sociais aplicadas; $\mathrm{V}$ - formação técnica e profissional, conforme a Lei $\mathrm{n}^{0} 13.415$, de 16 de fevereiro de 2017 apresenta ao reformular o art. 36 da Lei nº 9.394, de 20 de dezembro de 1996.

Os itinerários formativos são estabelecidos de acordo com o sistema de ensino, e os estudantes não possuem a liberdade de escolher por maior afinidade o itinerário formativo, mas conforme a disponibilidade de cada unidade escolar (BRASIL, [2017a], [2019]).

Em uma conjuntura caracterizada pela expansão da ideologia da Escola sem Partido, de avanço de forças conservadoras, de fechamento de fóruns e representações, e de políticas nefastas para a Educação, os estudantes secundaristas se mobilizaram e reivindicaram ser ouvidos para participarem das discussões sobre a Reforma do Ensino Médio.

No Paraná, segundo informações disponíveis no site do Movimento Ocupa Paraná (MAPA..., [2016?]), foram ocupadas cerca de 850 escolas, 14 universidades e três Núcleos Regionais de Educação. Não obstante, as informações veiculadas no jornal impresso de maior circulação no estado apontavam os dados fornecidos pela Secretaria de Estado da Educação, informando que, dentre as 2.147 escolas da rede estadual de ensino do Paraná, apenas 590 foram ocupadas (TUDO..., 2016; MAPA..., [2016?]). A Figura 1 apresenta a concentração das escolas ocupadas no Estado. 
Figura 1 - Maior concentração de escolas ocupadas no Estado do Paraná em outubro de 2016

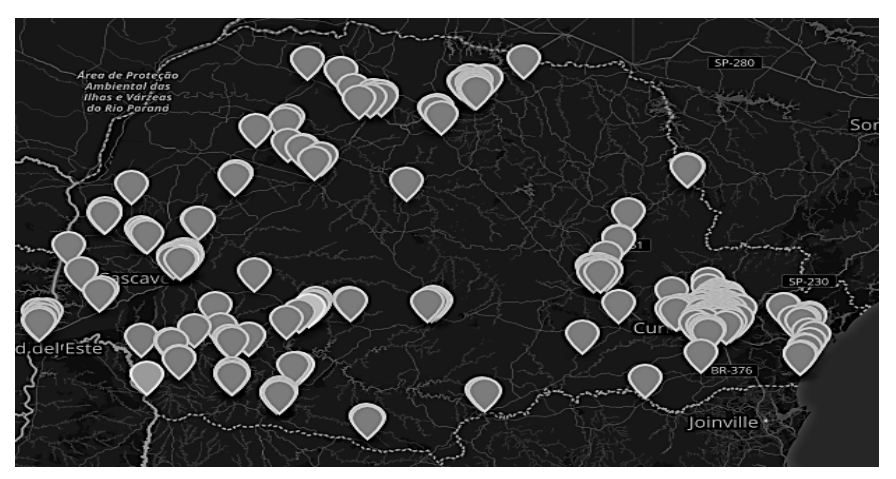

Fonte: Mapa das escolas ocupadas no Paraná, 2016.

As ocupações se expandiram e duraram alguns meses. Entretanto, na primeira quinzena de novembro de 2016, com o apoio da mídia, iniciaram-se as desocupações, por meio do cumprimento de mandados judiciais para reintegração de posse. O Estado do Paraná acionou o Judiciário e passou a reivindicar sua reintegração de posse, alegando que as ocupações das escolas estaduais pelos estudantes secundaristas envolviam esbulho ${ }^{2}$ e feriam o direito à educação, porque interrompiam o calendário escolar da maioria dos alunos. Ora, essa justificativa ocultava o motivo real da ocupação das escolas, porque impedia a compreensão por todos de como uma determinada relação social se torna dominante no seio da '[...] 'questão social' [que] envolve os confrontos estabelecidos entre as classes fundamentais do capitalismo - proletariado e burguesia - e que se transmutam, na vida cotidiana, em diversas refrações que atingem os trabalhadores". (DURIGUETTO; BALDI, 2012, p. 194).

Nessa direção, a ciência e os especialistas de Estado da burguesia possuem um papel essencial, visto que contribuem para fundamentar e legitimar o Estado de ideologia única, ao apresentar o conhecimento e as soluções objetivas das coisas, sob o argumento da neutralidade ideológica, da naturalização das coisas e da sua universalização. Esse argumento visa justificar as práticas de dominação e subordinação por meio de leis científicas e do aparato jurídico.

Os especialistas do Estado burguês operam com a burocracia, pretensamente neutra e colocada acima do cidadão, assumem o lugar de uma classe universal promotora do bem comum. Mészáros (2012, p. 60) intitula esses especialistas como os "[...] guardiães "neutros" [...]" da justiça.

No que diz respeito às ações de reintegração de posse das escolas ocupadas pelos estudantes secundaristas no Paraná, observou-se que os especialistas do Estado burguês trouxeram certo refinamento para os argumentos jurídicos nas ações de reintegração de posse, invertendo o real quando utilizaram o mesmo argumento dos estudantes secundaristas para solicitar a reintegração de posse forçada sob a justificativa do cumprimento do direito à educação, ou seja, apresentavam ideologicamente uma inversão do real, convertendo as manifestações dos estudantes e a luta pelo direito à educação em (des)obediência e assunto de força policial.

O caráter ideológico em um dos processos de reintegração de posse das escolas apresentava diversas armadilhas, uma delas era fazer a defesa laudatória da democracia, do direito de reunião e livre manifestação como pressupostos de um Estado Democrático; de outro lado, o juiz expedia mandado de justiça para que os oficiais, juntamente com a polícia militar, intimassem os manifestantes e impusessem multas àqueles que não desocupassem as escolas. A finalidade era muito mais do que intimar e multar, o foco estava em identificar os manifestantes para atribuir-lhes culpa e as suas punições, visto que são estudantes, filhos da classe trabalhadora, que na sua maioria não possuem as condições objetivas para viver uma vida sem privação. A questão colocada nas ações é inseparável da luta de classes.

Conforme declara o juiz, em 4 de novembro de 2016, e manda ao Oficial de Justiça:

CITAR os Requeridos que ali se encontrarem, na forma do art. 564, do NCPC, a fim de que, querendo, ofereçam contestação, no prazo legal, devendo o Sr. Meirinho, identificar os manifestantes, na medida do possível, para a complementação do polo passivo. Com relação aos ocupantes eventualmente não identificados, citem-se via edital a teor do disposto no $\S 1^{\circ}$, do art. 554., de todo o conteúdo da petição inicial e do despacho [...], para, querendo, na forma pugnada, apresentar defesa no prazo de 15(quinze) dias, ofereça resposta (art. 335 do NCPC), por meio de advogado, sob pena de revelia e confissão quanto à matéria de fato (art. 344 do NCPC) salvo nas hipóteses do art. 354 do NCPC [...] (PARANÁ, 2016c, grifo nosso, grifo do autor). 
A decisão do juiz supracitada se pauta na ideologia do terror, criando um clima de profundo medo, cercando por todos os lados os estudantes secundaristas, os quais passaram da condição de estudantes em luta pelo direito à educação à condição de réus, num processo que envolve advogado, confissão etc., combinado com ações violentas, pois na continuidade do texto, menciona que "fica autorizado, [...] em havendo necessidade, [...] arrombamento e reforço policial”. (PARANÁ, 2016c).

Ora, considera-se perversa a ação dos aparelhos jurídico e policial, visto que as razões dos estudantes secundaristas, filhos de trabalhadores, eram pelo direito de serem ouvidos, participarem do debate sobre a Reforma do Ensino Médio, pela defesa de um projeto de educação que não os considerasse como mercadoria e por uma escola pública que atendesse as suas necessidades específicas. Não obstante, os especialistas do Estado burguês omitiram as demandas dos estudantes secundaristas, visto que as ações não discutiam nada referente às razões mencionadas pelos estudantes, pelo contrário, as justificativas por parte do aparato judicial ancoravam-se no mito da neutralidade ideológica e na ideologia do terror, com a finalidade de fortaleceram os consensos na consecução do projeto da fração de classe que detém hegemonia.

N'A Ideologia Alemã, Marx e Engels (2007, p. 93, grifo do autor) mencionam que "a estrutura social e o Estado provém constantemente do processo de vida de indivíduos determinados, mas desses indivíduos não como podem aparecer na imaginação própria, ou alheia, mas sim tal como realmente são [...] como produzem materialmente [...]". A relação entre o ideal e o real, para Marx e Engels, as ideias, os valores, as representações correspondem a uma consciência social de um determinado tempo histórico e não representam a elaboração de uma razão independente. Quando uma determinada consciência expressa sua visão de mundo, manifesta-se aí a materialidade em que esta consciência está inserida.

Essa materialidade é constituída pela luta de classes, portanto, é no interior da luta de classes que se forma a ideologia como consciência prática inescapável, conforme aponta Mészáros (2008, p. 9, grifo do autor):

A ideologia como, forma específica de consciência social é inseparável das sociedades de classe. Ela se constitui como consciência prática inescapável de tais sociedades, vinculada à articulação dos conjuntos de valores e estratégias rivais que visam ao controle do metabolismo social sobre todos os principais aspectos. Os interesses sociais, que se revelam ao longo da história e que se entrelaçam de modo conflitante, encontram suas manifestações no plano da consciência social na grande diversidade do discurso ideológico, relativamente autônomo (mas, de forma nenhuma, independente) com seu impacto poderoso mesmo sobre os processos materiais mais tangíveis do metabolismo social.

A consciência social como consciência prática inescapável se constitui nas relações sociais estabelecidas entre os homens, as quais não são harmônicas e nem lineares, visto que há diversos interesses e conflitos entre as classes sociais, entretanto, "[...] a classe que é força material dominante da sociedade é, ao mesmo tempo, sua força espiritual dominante". (MARX; ENGELS, 2007, p. 47, grifo do autor).

Nesse sentido, as relações sociais que os homens travam para produzir suas vidas, no modo de produção capitalista, se fazem sob o caráter de alienação (MARX, 2010). É a partir da alienação que o termo ideologia se origina e refere-se à consciência de um ser humano que apresenta uma visão de mundo alienada.

O trabalhador se torna tanto mais pobre quanto mais riqueza produz, quanto mais a sua produção aumenta em poder e extensão. $\mathrm{O}$ trabalhador se torna uma mercadoria tão mais barata quanto mais mercadorias cria. Com a valorização do mundo das coisas (Sachenwelt) aumenta em proporção direta a desvalorização do mundo do homens (Menschenwelt). O trabalho não produz somente mercadorias; ele produz a si mesmo e ao trabalhador como uma mercadoria, e isto na medida em que produz, de fato, mercadorias em geral. (MARX, 2010, p. 80, grifo do autor).

A relação que Marx expõe é que o produto já é estranhado a quem o produz e quando esse produto entra em circulação, oprime o produtor, o qual não tem acesso ao produto do seu trabalho. $O$ trabalho se manifesta no objeto produzido e deixa de pertencê-lo. Para Marx, a alienação econômica é a mais substancial, porque oculta as relações sociais de trabalho entre os homens, mais do que isso, a alienação econômica produz o estranhamento de todas as forças humanas. Como a ideologia deriva da alienação, trata-se, então, de uma ideologia que expressa a consciência de um ser humano que se alienou de si e do gênero humano.

O processo de alienação está vinculado à natureza da propriedade privada, à relação entre a atividade humana e as condições objetivas, pois os homens e mulheres só conseguem objetivar-se, tornarem-se humanos, numa sociedade em que os meios para produzir a vida satisfaçam as necessidades de todos os indivíduos e, para isso, faz-se necessário romper com a propriedade privada. A aniquilação da propriedade privada é “[...] a emancipação completa de todas as qualidades e sentidos humanos; mas ela é esta emancipação justamente 
pelo fato desses sentidos e propriedades terem se tornado humanos, tanto subjetivamente quanto objetivamente". (MARX, 2010, p. 109, grifo do autor).

Nesse contexto, a posse serviu como meio para as ações de reintegração de posse das escolas ocupadas pelos secundaristas, ou seja, estava em jogo o direito à propriedade e à posse. Sabe-se que uma ação de reintegração de posse é uma ação em que aquele que é o possuidor de um bem alega que o seu direito está sendo violado e está perdendo a posse em virtude do esbulho. Trata-se, então, de acordo com o Direito formal, de uma ação sobre a propriedade, a violação de posse e a restituição do esbulho, para assumir a posse novamente.

As ações de reintegração de posse das escolas estaduais analisadas foram ajuizadas pelo Estado do Paraná, o qual alegava e comprovava que exercia a posse sobre as escolas. Foram analisados seis processos de reintegração de posse nos municípios de Colombo, São José dos Pinhais, Goioerê, Tomazina, Fazenda Rio Grande e Campo Largo. Todas as ações judiciais das escolas ocupadas nesses municípios alegam o esbulho, a perda de posse, e, em seguida, expedem uma ordem de reintegração de posse.

No processo 0003975-56.2016.8.16.0193, Classe Procedimento Ordinário, Vara da Fazenda Pública de Colombo, o juiz, em 4 de novembro de 2016, manifestou-se:

INTIMAR da liminar de REINTEGRAÇÃO DE POSSE concedida dos colégios/escolas relacionados na inicial, concedendo o prazo de 24 (vinte e quatro) horas para a desocupação voluntária. Superando o prazo fixado e persistindo o esbulho aqui verificado, expeça-se o competente mandato para a reintegração forçada da posse dos colégios/escolas relacionadas na inicial, ficando o Sr. Oficial de Justiça autorizado a proceder na forma prevista no art 212, do NCPC. Fica autorizado, outrossim, em havendo necessidade, 0 cumprimento do mandado com ordem de arrombamento e reforço policial. Desde logo, fica fixado o valor de $\mathbf{R} \$ 250,00$ (duzentos e cinquenta reais) a título de multa diária para o caso de descumprimento da medida. (PARANÁ, 2016c, grifo nosso, grifo do autor).

Para acompanhar a decisão supracitada sobre a reintegração de posse nos colégios estaduais de Colombo, é expedido ofício ao comandante da Polícia Militar para que providencie o reforço policial necessário (PARANÁ, 2016d) e para a Ordem dos Advogados do Brasil de Colombo:

REINTEGRAÇÃO DE POSSE em que é Requerente ESTADO DO PARANÁ, e Requerido UPES - UNIÃO DOS ESTUDANTES SECUNDÁRIOS e INVASORES DESCONHECIMENTOS, dou ciência a Vossa Senhoria, da decisão que deferiu a liminar no presente feito, visto que a situação envolve interesses de pessoas incapazes ou relativamente incapazes, além de clamor social [...] (PARANÁ, 2016e, grifo nosso, grifo do autor).

Vale destacar que, nesse contexto, alguns diretores das escolas estaduais de Colombo acionaram a polícia militar, por meio da patrulha escolar, para comunicar a ocorrência de que as escolas foram invadidas, ocupadas por menores, os quais estavam impedindo alunos, professores e funcionários de trabalharem. Um dos Boletins de Ocorrência (B.O.) apresentava, na descrição, as razões, ao passo que os outros apenas informavam a invasão. A exemplo do B.O. n. ${ }^{\circ} 2016 / 1124331$, “[...] foi ocupado pelos alunos que fazem parte do Movimento Ocupa Paraná, que protestam contra a Reforma do Ensino Médio. A ocupação se deu de forma pacífica, porém as aulas [...] ficaram comprometidas por conta das manifestações". Outro B.O., sob o n. ${ }^{\circ}$ AF 701874, menciona o seguinte: "fomos acionados pelo diretor do colégio, que relatou que o colégio foi invadido por alunos e pessoas da comunidade e que os invasores não permitem nem alunos e nem funcionários".

O esbulho é a justificativa central em todas as ações de reintegração de posse, que para o judiciário se sustenta nos boletins de ocorrência, os quais denotam o fato da ocupação, e argumentam que o Estado do Paraná tem a posse porque presta serviço público educacional.

Ora, há um feito contrário nessas ações, uma inversão, no sentido de que a culpa é dos estudantes invasores, e não se quer discutir as raízes que produzem as mobilizações. O discurso oficial responsabiliza os estudantes por esbulho e por ferirem o direito à educação. Ao colocar a ênfase nos invasores sob a justificativa de que são eles que interrompem o acesso de todos à escola, logo, são os que prejudicam a si e aos colegas, impedindo-os de concluir o ano letivo, realizar o Exame Nacional do Ensino Médio (ENEM), enfim, concluir seus estudos e permitir aos professores e funcionários trabalharem. As justificativas nas ações de reintegração de posse insistiam permanentemente na culpabilização dos estudantes invasores, lançando a mensagem que a maioria dos estudantes não concorda com as ocupações, e que elas têm relação com alguns partidos políticos. O judiciário e o Estado do Paraná, nesse contexto, desempenharam o papel de vítimas propiciatórias que iriam apaziguar os pecados dos estudantes, se atendessem ao clamor social e desocupassem as escolas pacificamente.

Nesse sentido, o caráter ideológico nas ações de reintegração de posse opera pelo ocultamento, quando os especialistas e o Estado se colocam como portadores da verdade, impedindo de compreender que a culpa 
não está nos indivíduos, mas nas determinações econômicas, políticas e sociais. Mediante essa ideologia, ocorre a expressão da inversão do real, pois não é o Estado que impede o direito à educação, mas os estudantes invasores que prejudicam a efetivação da educação pública. Por fim, a ideologia posta apresenta que se a desocupação não for voluntária, deve-se partir para a reintegração forçada, sob o uso de arrombamento, multa e reforço policial. Aqui não há nada de novo, quando a ideologia é a apresentação de que a reintegração de posse é a única possibilidade que existe e assim deve ser.

Marx e Engels (2007, p. 48), revelam como opera a ideologia dominante nas relações sociais:

[...] as ideias que dominam são cada vez mais abstratas, isto é, que assumem cada vez mais a forma da universalidade. Realmente toda a nova classe que toma o lugar de outra que dominava anteriormente é obrigada, para atingir seus fins, a apresentar seu interesse como o interesse comum de todos os membros da sociedade, quer dizer, expresso de forma ideal: é obrigada a dar à suas ideias a forma da universalidade, e apresentá-las como as únicas racionais, universalmente válidas.

Uma das formas de como a ideologia dominante age é que ela expressa o que é particular como se fosse o universal, portanto, conectado aos interesses comuns. A burguesia consegue fazer isso, porque oculta as determinações históricas, econômicas, sociais, políticas e culturais e, ao ocultá-las, difunde que as relações sociais correspondem imediatamente ao real e isto se apresenta como algo natural, como se fosse expressão da força da natureza e/ou próprio da natureza humana e não como uma correspondência da relação de dominação. A naturalização das relações impede a possibilidade de mudança das coisas, visto que difunde que há uma única saída e elas são apresentadas como inevitáveis.

A finalidade da burguesia quando apresenta o particular como universal nada mais é do que garantir a reprodução das relações de dominação sobre a classe trabalhadora.

Outra forma como opera a ideologia para Marx e Engels (2007, p. 94) é por meio da inversão das coisas, "se, em toda ideologia, os homens e suas relações aparecem de cabeça para baixo como numa câmara escura, esse fenômeno resulta do seu processo histórico de vida, da mesma forma como a inversão dos objetos na retina resulta de seu processo de vida físico". Ora, a inversão não emerge na ideologia, mas há uma inversão do real que se apresenta ideologicamente.

Por sua vez, os pensadores, os ideólogos, enquanto produtores de ideias, "[...] regulam a produção e a distribuição das ideias de seu tempo; e, por conseguinte, que as suas ideias são as

[...] as ações de reintegração de posse [...] converteram as manifestações dos estudantes e a luta pelo direito à educação em (des)obediência e assunto de força policial. ideias dominantes da época". (MARX; ENGELS, 2007, p. 47).

Esses pensadores, ideólogos, utilizam de uma "[...] camuflagem ideológica enganadora [...]" que passa a sensação de que são neutros e de que há uma "[...] neutralidade ideológica [...]" (MÉSZÁROS, 2012, p. 13). Nesse sentido, difundem um conjunto de ideias ${ }^{3}$, representações, conceitos e imagens de que só existe uma única realidade e uma única reposta para intervir nessa realidade, tampouco há alternativas para pensar outras possibilidades de intervir no real.

Rancière (2014) assinala que a ciência e os especialistas de Estado possuem um papel essencial, pois geralmente contribuem para fundamentar e legitimar o Estado de ideologia única, ao apresentar o conhecimento e as soluções objetivas das coisas, sob o argumento da neutralidade ideológica, da naturalização das coisas e da sua universalização. Esse argumento visa justificar as práticas de dominação e subordinação por meio de leis científicas e do aparato jurídico.

Por outro lado, as ações de reintegração de posse não intimidaram os estudantes, pelo contrário, conforme aponta o Agravo de Instrumento $n .^{\circ} 1596910-3$ (PARANÁ, 2016a), o movimento de ocupação das escolas em forma de "[...] manifestação e protesto contra a Medida Provisória sobre a reforma do Ensino Médio ocorreu com maior intensidade no Estado do Paraná"; e o documento continua, mencionando que ele vem "[...] perdendo força com a desocupação contínua [...]". Ora, tal afirmação não expressa o real, visto que, no município de Ponta Grossa, todas as desocupações ocorreram sob reintegração forçada, e os estudantes seguiam para outras escolas, unindo-se a outros estudantes e sob o apoio da Seção Sindical dos Docentes da Universidade Estadual de Ponta Grossa (SINDUEPG), a qual organizou oficinas com os professores da Universidade Estadual de Ponta Grossa (UEPG) sobre a Medida Provisória, a PEC 55, trabalhou conteúdos específicos de cada disciplina e também os ancorava com as condições objetivas para garantir a permanência nas escolas. 
Nesse sentido, Marx e Engels (1998, p. 48) nos ajudam a compreender que "a burguesia fornece aos proletários os elementos de sua própria educação política, isto é, armas contra ela própria". As escolas ocupadas, na sua maioria, não sofreram nenhum atentado ao patrimônio público, o inverso do que foi exposto no processo 0003975-56.2016.8.16.0193 (PARANÁ, 2016f), e contido na Ata n. ${ }^{\circ}$ 17/2016 (PARANÁ, 2016b), referente à Assembleia do Conselho Escolar sobre a Ocupação do Colégio no dia 30/10/2016, que reforça que não há interesse, por parte dos estudantes, em deteriorar a escola, pelo contrário:

O aluno Lucas comentou que eles não estão ocupando a escola com objetivo de baderna nem bagunça, o principal objetivo é a luta contra a PEC, disse que a greve dos professores também prejudicou as aulas. Segundo ele, estão sofrendo críticas de pais e alunos, não privaram a entrada de ninguém, o colégio estava aberto a todos. Reafirmou a luta deles que também vai ajudar o ensino Fundamental. Em seguida, os alunos chamaram as professoras da UFPR para conversar com a comunidade e falar um pouco sobre a Medida Provisória e sobre a PEC 241, que agora passou a ser PEC 55. [...] [A professora] finalizou dizendo que o movimento dos "meninos" é importantíssimo e se os pais se juntarem a esta luta pode acontecer a retirada da PEC. (PARANÁ, 2016b).

Todos os dados mencionados de certa forma mostram que a ideologia burguesa e os seus "[...] guardiães "neutros" [...]" (MÉSZÁROS, 2012, p. 60) não operam para garantir o direito à educação dos filhos dos trabalhadores que estudam nas escolas públicas, pelo contrário, sua ideologia opera para garantir a manutenção e o domínio das relações sociais de uma classe sobre a outra. As leis ocultam os interesses da classe burguesa, convertendo as manifestações dos estudantes e a luta pelo direito à educação em (des)obediência e assunto de força policial. Contudo, os estudantes enfrentaram essa batalha judicial e a ideologia veiculada pelo Estado, pela mídia e pela comunidade escolar, um exemplo disso foi uma estudante, representante do Movimento Ocupa Paraná, que fez um pronunciamento na Assembleia Legislativa do Paraná, destacando que "A medida provisória [que prevê a reforma do ensino médio] não vai ser a melhor coisa pra gente. Nós queremos um canal de diálogo, para que a gente possa participar dessa construção". (RIBEIRO, 2016 apud ANÍBAL, 2016).

\section{Considerações Finais}

Neste artigo interpelou-se e problematizaram-se as razões avocadas para a reintegração de posse das escolas estaduais do Paraná pelos aparelhos jurídico e policial, levando em conta seu caráter ideológico. As razões para a reintegração de posse se ancoravam no pressuposto do esbulho e do argumento de que feriam o direito à educação, porque interrompiam o calendário escolar da maioria dos alunos.

Explicitou-se o caráter ideológico dessas razões, as quais ocultavam o motivo real das ocupações das escolas, porque impediam a compreensão por todos dos conflitos entre as classes. Por sua vez, os especialistas do Estado da burguesia se colocavam neutros e assumiam um argumento universal de que seus interesses correspondiam aos interesses comuns.

Apontou-se, também, que o aparato jurídico promoveu, nas ações de reintegração de posse, inverter o real, utilizando os mesmos argumentos dos estudantes secundaristas para solicitar a reintegração forçada sob o pressuposto do direito à educação, convertendo as mobilizações em (des)obediência e assunto de força policial.

Os processos traziam diversas armadilhas: se por um lado faziam a defesa laudatória da democracia, de outro lado, utilizavam a ideologia do terror para intimidar e identificar os estudantes de modo a instituírem punições com a finalidade de fortalecerem os consensos para que a classe que detém a hegemonia obtivesse êxito.

Explicitou-se também a permanente culpabilização dos estudantes, denominados invasores, e que o judiciário e o Estado do Paraná se colocavam no papel de vítimas propiciatórias que iriam apaziguar os pecados dos estudantes. Para isso, os estudantes deveriam escutar o clamor social e desocupar pacificamente as escolas.

Em síntese, ao retirar as máscaras e os remendos da ideologia burguesa presente nas razões avocadas para as ações de reintegração de posse, o que permanece são os conflitos de classe e a investida de práticas de dominação e subordinação por meio de leis científicas, do aparato jurídico e policial.

\section{Referências}

ANÍBAL, F. Conheça a aluna que discursou na Assembleia Legislativa em defesa da ocupação das escolas. Gazeta do Povo, Curitiba, 27 out. 2016. Disponível em: https://www.gazetadopovo.com.br/vida-e-cidadania/conheca-a-aluna-que-discursou-na-assembleia-legislativaem-defesa-da-ocupacao-das-escolas-cau79btxgxx9wd6ku73gjcjo2/. Acesso em: 25 maio 2018. 
BENASSE, P. R. Dicionário jurídico de bolso. 2. ed. Campinas: Bookseller, 2001.

BRASIL. Lei $n^{\circ}$ 9.394, de 20 de dezembro de 1996. Estabelece as diretrizes e bases da educação nacional. Brasília, DF: Presidência da República, [2019]. Disponível em: http://www.planalto.gov.br/ccivil_03/LEIS/L9394.htm. Acesso em: 20 mar. 2019.

BRASIL. Lei $n^{\circ} 13.415$, de 16 de fevereiro de 2017. Altera as Leis ${ }^{\circ}$ 9.394, de 20 de dezembro de 1996, que estabelece as diretrizes e bases da educação nacional, e 11.494, de 20 de junho 2007, que regulamenta o Fundo de Manutenção e Desenvolvimento da Educação Básica e de Valorização dos Profissionais da Educação, a Consolidação das Leis do Trabalho - CLT, aprovada pelo Decreto-Lei no 5.452 , de $1^{\circ}$ de maio de 1943, e o Decreto-Lei n ${ }^{\circ} 236$, de 28 de fevereiro de 1967; revoga a Lei n ${ }^{\circ} 11.161$, de 5 de agosto de 2005; e institui a Política de Fomento à Implementação de Escolas de Ensino Médio em Tempo Integral. Brasília, DF: Presidência da República, [2017a]. Disponível em: http://www.planalto.gov.br/ccivil_03/_Ato2015-2018/2017/Lei/L13415.htm. Acesso em: 20 mar. 2019.

BRASIL. Medida Provisória $n^{\circ}$ 746, de 22 de setembro de 2016. Institui a Política de Fomento à Implementação de Escolas de Ensino Médio em Tempo Integral, altera a Lei n 9.394, de 20 de dezembro de 1996, que estabelece as diretrizes e bases da educação nacional, e a Lei n ${ }^{\circ} 11.494$ de 20 de junho 2007, que regulamenta o Fundo de Manutenção e Desenvolvimento da Educação Básica e de Valorização dos Profissionais da Educação, e dá outras providências. Brasília, DF: Presidência da República, [2017b]. Disponível em: http:// www.planalto.gov.br/ccivil_03/_Ato2015-2018/2016/Mpv/mpv746impressao.htm. Acesso em: 20 mar. 2019.

CHAUÍ, M. O que é ideologia. 2. ed. São Paulo: Brasiliense, 2008.

DURIGUETTO, M. L.; BALDI, L. A. P. Serviço Social, mobilização e organização popular: uma sistematização do debate contemporâneo. Revista Katálysis, Florianópolis, v. 15, n. 2, p. 193-202, jul./dez. 2012.

MAPA das escolas ocupadas no Paraná. OCUPAPARANA.ORG. [S. l.], [2016?]. Disponível em: http://ocupaparana.org/. Acesso em: 10 maio 2018.

MARX, K. Manuscritos econômicos-filosóficos. São Paulo: Boitempo, 2010.

MARX, K. Prefácio. In: MARX, K. Para a crítica da economia política. São Paulo: Expressão Popular, 2008. p. 45-50.

MARX, K; ENGELS, F. A ideologia alemã. São Paulo: Boitempo, 2007.

MARX, K.; ENGELS, F. Manifesto comunista. São Paulo: Boitempo, 1998.

MÉSZÁROS, I. Filosofia, ideologia e ciência social. São Paulo: Boitempo, 2008.

MÉSZÁROS, I. O poder da ideologia. São Paulo: Boitempo, 2012.

PARANÁ. Tribunal de Justiça do Estado do Paraná. AGRAVO DE INSTRUMENTO No 1596910-3, DE SÃO JOSÉ DOS PINHAIS VARA DA FAZENDA PÚBLICA. Processo 0003975-56.2016.8.16.0193. Comarca da Região Metropolitana de Curitiba. Vara da Fazenda Pública de Colombo. 3 nov. 2016a. PROJUDI. Chave de Validação: PJZRA 6XKL8 YG2XY MLL7K.

PARANÁ. Tribunal de Justiça do Estado do Paraná. ATA No 17/2016 Assembleia do Conselho Escolar sobre a Ocupação do Colégio. Processo 0003975-56.2016.8.16.0193. Comarca da Região Metropolitana de Curitiba. Vara da Fazenda Pública de Colombo. 3 nov. 2016b. PROJUDI. Chave de Validação: PJYAT ZED2A DQJGY J5W6Y.

PARANÁ. Tribunal de Justiça do Estado do Paraná. Mandado de citação, identificação e reintegração de posse. Processo 000397556.2016.8.16.0193. Comarca da Região Metropolitana de Curitiba. Vara da Fazenda Pública de Colombo. 4 nov. 2016c. PROJUDI. Chave de Validação: PJ6L3 5Q2N6 2N3CW 7YZBR.

PARANÁ. Tribunal de Justiça do Estado do Paraná. Ofício no 344/2016. Processo 0003975-56.2016.8.16.0193. Comarca da Região Metropolitana de Curitiba. Vara da Fazenda Pública de Colombo. 4 nov. 2016d. PROJUDI. Chave de Validação: PJZL GKL2 6QCZ UV46 92UR.

PARANÁ. Tribunal de Justiça do Estado do Paraná. Oficion ${ }^{\circ}$ 353/2016. Processo 0003975-56.2016.8.16.0193. Comarca da Região Metropolitana de Curitiba. Vara da Fazenda Pública de Colombo. 4. nov. 2016e. PROJUDI. Chave de Validação: PJ8F DWXT 7CSC EH7Y DZJU.

PARANÁ. Tribunal de Justiça do Estado do Paraná. Processo 0003975-56.2016.8.16.0193. Comarca da Região Metropolitana de Curitiba. Vara da Fazenda Pública de Colombo. 2016f. PROJUDI.

RANCIÈRE, J. O ódio à democracia. São Paulo: Boitempo, 2014.

TUDO sobre a greve e a ocupação nas escolas do Paraná. Gazeta do Povo, Curitiba, 27 out. 2016. Disponível em: http:// www.gazetadopovo.com.br/educacao/tudo-sobre-a-greve-e-a-ocupacao-nas-escolas-do-parana-b6t39taw4sm8yw0yq418q379u. Acesso em: 25 maio 2018

\section{Notas}

1 Segundo Chauí (2008), o termo ideologia foi utilizado pela primeira vez na França, em 1801, por Antonie Destutt de Tracy, um naturalista, para se referir à ciência das ideias e a relação do corpo com a sociedade. O grupo de Tracy era crítico acerca da metafísica e do poder dos reis. Napoleão Bonaparte utiliza esse termo para fazer uma crítica em referência aos intelectuais franceses que se encontravam afastados da realidade, incluindo Destutt de Tracy. Contudo, essa crítica era infundada e invertia a imagem dos ideólogos que se intitulavam materialistas. Apesar disso, conforme Chauí (2008), conceito de ideologia ganha força no início do século XIX, quando Marx e Engels se apropriam desse termo e passam a se dedicar à filosofia, à política e à cultura alemã. É a partir desse momento que o termo ideologia ganha um novo sentido, que é fazer a crítica da ideologia alemã. Ademais, essa ressignificação se constitui sob a influência de duas correntes filosóficas, Ludwig Feuerbach, o qual fazia a crítica à religião, e de outro lado a filosofia de Hegel, com a crítica das ilusões do conhecimento (CHAUÍ, 2008). Imbuídos por essas duas vertentes e a condição 
do materialismo prático que se instaurava, Marx e Engels se defrontaram com a necessidade de explicitar como se formavam as ideologias.

2 De acordo com o Benasse (2001, p. 168), esbulho é o "ato violento pelo qual o possuidor é retirado, sem sua anuência ou justificativa, de sua posse". No caso, o Estado do Paraná é retirado da posse de guardião da escola pública.

$3 \operatorname{Marx}(2010)$ defende a tese de que, ao mesmo tempo em que o conjunto de representações, conceitos e imagens constituem a ideologia, é por meio dessas representações e conceitos que a humanidade apreende as contradições e ao apreendê-la cria alternativas para enfrentá-las.

\section{Patrícia Correia de Paula Marcoccia}

pa.tyleo12@gmail.com

Doutorado em Educação pela Universidade Tuiuti do Paraná (UTP)

Professora do Departamento de Pedagogia e do Programa de Pós-Graduação em Educação da Universidade Estadual de Ponta Grossa (UEPG)

\section{UEPG}

Praça Santos Andrade, 1 - Centro

Ponta Grossa - Paraná - Brasil

CEP: $84.010-330$

\section{Maria de Fátima Rodrigues Pereira}

maria.pereira@utp.br

Doutorado em Filosofia e História da Educação pela Universidade Estadual de Campinas (Unicamp)

Professora do Programa de Pós-Graduação em Educação na Universidade Tuiuti do Paraná (UTP)

\section{UTP}

Rua Sydnei Antônio Rangel Santos, 238 - Santo Inácio

Curitiba - Paraná - Brasil

CEP: $82.010-330$

\section{Rodrigo Diego de Souza}

professor.rodrigosouza@gmail.com

Mestrado em Ensino de Ciência e Tecnologia pela Universidade Tecnológica Federal do Paraná (UTFPR)

Professor do Departamento de Metodologia de Ensino do Centro de Ciências da Educação da Universidade

Federal de Santa Catarina (UFSC)

\section{UFSC}

Campus Universitário Reitor João David Ferreira Lima - Trindade

Florianópolis - Santa Catarina - Brasil

CEP: $88.040-900$

\section{Agência financiadora \\ Não se aplica.}

\section{Contribuições dos autores}

Patrícia: coleta de dados e a escrita sobre os processos de reintegração de posse e ideologia.

Maria de Fátima: coleta de dados e a escrita sobre ideologia.

Rodrigo: escrita sobre o Movimento Ocupa Paraná e legislação sobre Ensino Médio.
Aprovação por Comitê de Ética e consentimento para participação

Não se aplica.

Consentimento para publicação

Não se aplica.

Conflito de interesses

Não há conflito de interesses. 